\title{
Use of the loop-mediated isothermal amplification method for identification of PCR ribotype 027 Clostridium difficile
}

\author{
Correspondence \\ Haru Kato \\ cato@nih.go.jp
}

Received 27 December 2010

Accepted 25 March 2011

\author{
Haru Kato and Yoshichika Arakawa \\ Department of Bacteriology II, National Institute of Infectious Diseases, Tokyo, Japan
}

\section{INTRODUCTION}

Clostridium difficile is well known as an important cause of health-care-associated infection. The emergence of a $C$. difficile strain characterized as restriction endonuclease analysis (REA) type BI, PFGE type NAP1 and PCR ribotype 027 has been reported to be responsible in part for the epidemic in North America and Europe in the past decade (Kuijper et al., 2008; Loo et al., 2005; MacCannell et al., 2006; McDonald et al., 2005; Warny et al., 2005). In addition, it has been documented that patients infected with this strain are more likely to develop severe disease (Barbut et al., 2007; Goorhuis et al., 2007). Since the epidemic by PCR ribotype 027 threatens to extend to the rest of the world including Asia (Gerding, 2010), early recognition of the emergence of the strain is valuable (Goorhuis et al., 2007), especially in the countries or areas where the strain is not currently epidemic.

In previous studies, a system for typing $C$. difficile by sequencing the gene encoding the surface-layer protein A $(\operatorname{slp} A)$ was established and evaluated (Kato et al., 2010; Killgore et al., 2008). These reports documented that the typing results exhibited a high concordance with those obtained by PCR ribotyping; slpA sequence type gc8 corresponded to PCR ribotype 027 (Kato et al., 2010; Killgore et al., 2008). In the present study, we established a simple method for identification of PCR ribotype 027 by

Abbreviations: CDT, binary toxin; LAMP, loop-mediated isothermal amplification; REA, restriction endonuclease analysis.

The GenBank/EMBL/DDBJ accession numbers (s/pA sequence type) for the s/pA genes reported in this study are AB249986 (gc8-01), AB257285 (gc8-02), AB257286 (gc8-03), AB461839 (gc8-05) and AB461840 (gc8-06). loop-mediated isothermal amplification (LAMP) detecting the $\operatorname{slp} A$ gene of $\operatorname{slp} A$ sequence type gc8 strains $(\operatorname{slp} A-g c 8)$.

\section{METHODS}

Bacterial strain. A total of 107 C. difficile isolates were examined. The reference strains of serogroups A (ATCC 43594), C (ATCC 43596), F (ATCC 43598), G (ATCC 43599) and H (ATCC 43600) (Delmée et al., 1986) were obtained from the American Type Culture Collection. The 59 clinical $C$. difficile isolates used in this study were isolated from various hospitals in Japan. A collection of 42 isolates used for a previous study including strain US42 (REA type BI/PFGE type NAP1/PCR ribotype 027; Killgore et al., 2008) and strain UMCG12(3) (PCR ribotype 078; Goorhuis et al., 2008) were tested as well.

PCR detecting the toxin genes. The non-repeating and repeating sequences of the toxin A gene $(t c d A)$ were amplified by PCR with primer sets NK3-NK2 (Kato et al., 1991) and NK9-NK11-NKV011 (Kato et al., 1998, 1999), respectively. The isolates were identified as toxin A-negative when PCR with the primer set NK3-NK2 was negative (Kato et al., 1991). When PCR by the NK3-NK2 primer set was positive and PCR by the NK9-NK11-NKV011 primer set generated an amplification product of approximately $1200 \mathrm{bp}$ in size, the isolates were identified as toxin A-positive. When PCR by NK3-NK2 was positive and the product by PCR with NK9-NK11-NKV011 was approximately $700 \mathrm{bp}$ in size, the isolates were identified as toxin Anegative (Kato et al., 1998, 1999). When the isolates were positive for PCR by NK3-NK2 but the PCR product generated by NK9-NK11NKV011 was neither approximately $1200 \mathrm{bp}$ nor $700 \mathrm{bp}$ in size, toxin production by the isolates was determined. The presence of the nonrepeating sequences of the toxin $B$ gene $(t c d B)$ was examined by PCR using primer set NK105-NK104 (Kato et al., 1998). PCR detection of the gene encoding the binding component of binary toxin (CDT) was performed as previously described (Stubbs et al., 2000).

Determination of toxin production by isolates. $C$. difficile was cultured anaerobically in brain-heart infusion broth (Becton 
Dickinson) for 5 days. Toxin A was detected by an enzyme immunoassay kit, C. difficile toxin A test (Oxoid). Toxin B was detected by a culture assay using Vero cells and C. difficile goat antitoxin B serum was used for the neutralization test (Kato et al., 1998).

Typing of isolates. Typing of isolates by sequencing $s l p A$ was carried out as previously described (Kato et al., 2010). Isolates were assigned to different major types when they had 20 or more amino acid differences, and to subtypes (01-06) when they had fewer than 20 such differences. PCR ribotyping was performed by the modified methods of Stubbs and others as previously described (Kato et al., 2010; Stubbs et al., 1999).

Detection of $\boldsymbol{s} \mathbf{p} \boldsymbol{A} \mathbf{A}-\mathbf{g c \boldsymbol { s }}$ by LAMP. For DNA extraction for LAMP, $C$. difficile was inoculated on Brucella agar supplemented with vitamin $\mathrm{K}_{1}$ and haemin (Kyokuto Pharmaceutical) for 1-7 days anaerobically. A single colony was suspended in $50 \mu \mathrm{l}$ TES $(50 \mathrm{mM}$ Tris hydrochloride, $\mathrm{pH} 8.0 ; 5 \mathrm{mM}$ EDTA; and $50 \mathrm{mM} \mathrm{NaCl}$ ). The suspension was heated at $95{ }^{\circ} \mathrm{C}$ for $15 \mathrm{~min}$ and then centrifuged at $15000 \mathrm{~g}$ for $2 \mathrm{~min}$, and the resultant supernatant was used as a template for the LAMP assay. The six primers used for the LAMP were derived from the $s l p A$ gene of strain US42, which was identified as REA type BI, PFGE type NAP1, PCR ribotype 027 and $s l p A$ sequence type gc8-01 (GenBank accession no. AB249986) (Kato et al., 2010; Killgore et al., 2008). The outer primers used were gc8002a-F3 (5'-GCTCTCCAGCAGAGGGAG-3') and gc8002-B3 (5' -AGTTCCATCAACTAAACCAAAC- $\left.3^{\prime}\right)$; the inner primers were gc8002b-FIP $\left(5^{\prime}\right.$ TTGGAGCTGTATTTTTTGCTCCCGCAATAAAAGTAGCTACAAGTAG-3') and gc8002-BIP (5'-GTCTATGTCAGATGTATTTGATACATAAGTTTCACAGCAGTTTCAGT- $3^{\prime}$ ); and the loop primers were gc8002-FL ( $5^{\prime}$-TACCAGCATTTTCGACTTCACC- $\left.3^{\prime}\right)$ and gc8002-BL (5'-GCTTTTACAGATTCA-3'). The LAMP reaction was performed using the Loopamp DNA amplification kit (Eiken Chemical) according to the manufacturer's instructions. Two microlitres of DNA template was added to a total volume of $25 \mu$ buffer consisting of $5 \mathrm{pM}$ of each of the outer primers, $40 \mathrm{pM}$ of each of the inner primers and $20 \mathrm{pM}$ of each of the loop primers. Amplification was performed at $62{ }^{\circ} \mathrm{C}$ for $60 \mathrm{~min}$. The increased turbidity was monitored by a real-time turbidimeter, LA-320C (Eiken Chemical). The turbidity was calculated based on the ratio of light intensity (the intensity of light received by the photodiode/the emitted light intensity). The threshold of LAMP positive for the turbidimeter was defined as 0.1 .

Determination of the sequences of $t c d C$. The sequences of $t c d C$ were determined by sequencing the PCR product with primer set C1C2 as described previously (Spigaglia \& Mastrantonio, 2002). The primer set NK3-Lok1 (Braun et al., 1996; Kato et al., 1991) was used for sequencing $t c d C$ of isolate DJNS 7-18. The sequences obtained were compared to those of strain VPI 10463 and strain US42 as well as to the sequences previously described (MacCannell et al., 2006) and those in the GenBank database. The comparative analysis was performed by GENETYX-MAC version 12.2.3.

\section{RESULTS}

\section{Typing results}

Sequencing of the $\operatorname{slp} A$ gene resulted in 24 major types and 54 subtypes for the 107 isolates tested. Of the 107 isolates, 29 were typed as $s l p A$ sequence type gc8, and five different subtypes (slpA sequence types gc8-01, gc8-02, gc8-03, gc805 and gc8-06) were found among these 29 isolates (Table 1). Types gc8-01, gc8-02, gc8-03 and gc8-06 differed from each other by $1 \mathrm{nt}$, involving a single deduced amino acid. The $\operatorname{slp} A$ sequence of one isolate, DJNS 7-18, was found to differ from that of gc8-01 by eight deduced amino acids (slpA sequence type gc8-05). Among the 107 isolates, 48 different PCR ribotypes were identified. Of the 28 isolates belonging to gc8-01, gc8-02, gc8-03 or gc8-06, 27 were typed as PCR ribotype 027 (Fig. 1). One isolate of $s l p A$ sequence type gc8-01 (JND 10-61) was typed as a different PCR ribotype from PCR ribotype 027 (PCR ribotype 027r; Fig. 1), while its PCR banding pattern showed two band differences from that of 027. Isolate DJNS 7-18 and the remaining 78 isolates were typed into 46 different PCR ribotypes, banding patterns of which were distinct from that of PCR ribotype 027 . The epidemiologically important PCR ribotypes 001, 002, 014, 017, 078, trf and smz (Barbut et al., 2007; Goorhuis et al., 2008; Kato et al., 2010; Killgore et al., 2008) were included in the 46 PCR ribotypes.

\section{Detection of $s / p A-g c 8$ by LAMP}

$s l p A-g c 8$ was detected by LAMP in all 29 isolates of $\operatorname{slp} A$ sequence type gc8 including JND 10-61 and DJNS 7-18 (Fig. 2; Table 1). LAMP was performed on DNA extracted from strain US42, which was incubated for 1 or 7 days. The time for $C$. difficile culture to extract DNA did not affect the LAMP reaction. In a comparison of the LAMP results in 28 isolates identified as PCR ribotypes 027 and $027 \mathrm{r}$ (slpA sequence types gc8-01, gc8-02, gc8-03 and gc8-06), the amplification reaction in DJNS 7-18 (PCR ribotype tkm0718/slpA sequence type gc8-05) was slow (Fig. 2). LAMP was performed on 78 isolates of types other than slpA sequence type gc8 in a $90 \mathrm{~min}$ reaction, with negative results (Table 1). The sensitivity and specificity of the LAMP method for identification of PCR ribotype 027 were $100 \%$ and $98 \%$, respectively.

\section{s/pA sequence type gc8 isolates recovered in Japan}

Of seven $\operatorname{slp} A$ sequence type gc 8 isolates recovered in Japan, six (subtypes gc8-01 and gc8-06) were toxin A-positive, toxin B-positive and CDT-positive. Sequencing analysis of the six isolates including JND 10-61 detected $t c d C$ identical with that of strain US42 and published sequences (MacCannell et al., 2006). Isolate DJNS 7-18 (subtype gc8-05) was toxin A-negative, toxin B-positive and CDTpositive. In the DJNS 7-18 isolate, PCR using the NK3NK2 primer set was positive but no amplification was obtained by PCR using the NK9-NK11-NKV011 primer set. This isolate was tested by enzyme immunoassay for toxin A production, with a negative result, and toxin B was detected by a cell culture assay with a positive neutralization reaction. When the sequences of $t c d A$ and $t c d C$ were compared to those registered in the GenBank database, DJNS 7-18 had deletions in $t c d A$ and $t c d C$; the deletions were the same in location and size as those of strain 8864 (GenBank accession no. AJ011301). Isolate DJNS 7-18 was 
Table 1. Typing results and LAMP results for identification of PCR ribotype 027

\begin{tabular}{|c|c|c|c|c|c|c|c|}
\hline \multirow{2}{*}{$\begin{array}{l}\text { slpA sequence } \\
\text { major type }\end{array}$} & \multirow{2}{*}{$\begin{array}{l}\text { slpA sequence } \\
\text { subtype }\end{array}$} & \multirow[t]{2}{*}{ PCR ribotype } & \multirow[t]{2}{*}{ LAMP results } & \multicolumn{3}{|c|}{ No. of isolates tested from: } & \multirow{2}{*}{$\begin{array}{c}\text { Total no. of isolates } \\
\text { studied }\end{array}$} \\
\hline & & & & Japan & $\begin{array}{c}\text { North America and } \\
\text { Europe }^{\star}\end{array}$ & ATCC & \\
\hline \multirow[t]{6}{*}{ gc8 } & gc8-01 & 027 & + & 4 & 16 & & 20 \\
\hline & gc8-01 & $027 \mathrm{r} \dagger$ & + & 1 & & & 1 \\
\hline & gc8-02 & 027 & + & & 2 & & 2 \\
\hline & gc8-03 & 027 & + & & 4 & & 4 \\
\hline & gc8-05 & tkm0718 & $+\ddagger$ & 1 & & & 1 \\
\hline & gc8-06 & 027 & + & 1 & & & 1 \\
\hline Other types $\S$ & & & - & 52 & 21 & 5 & 78 \\
\hline Total & & & & 59 & 43 & 5 & 107 \\
\hline
\end{tabular}

${ }^{\star}$ A collection of 42 isolates used for a previous study (Killgore et al., 2008) and strain UMCG12(3) (PCR ribotype 078; Goorhuis et al., 2008). $\dagger$ The banding pattern of JND 10-61 (PCR ribotype 027r) differed from that of type 027 by two bands.

$\ddagger$ The LAMP reaction in DJNS 7-18 was slow.

$\$ A$ total of 78 isolates were typed into 23 slpA sequence major types, 49 slpA sequence subtypes and 45 PCR ribotypes.

recovered from a patient who suffered from pseudomembranous colitis in 2008 .

\section{DISCUSSION}

In the present study, all PCR ribotype 027 isolates tested were successfully identified by LAMP assay detecting the $s l p A-g c 8$ gene. The isolates typed as 47 different PCR ribotypes other than type 027 were all negative for LAMP with the exception of two isolates, JND 10-61 and DJNS 718. In JND 10-61, which was typed as $\operatorname{sip} A$ sequence gc801, the PCR ribotype pattern differed from that of type 027 by two bands and its $t c d C$ sequence was the same as that of

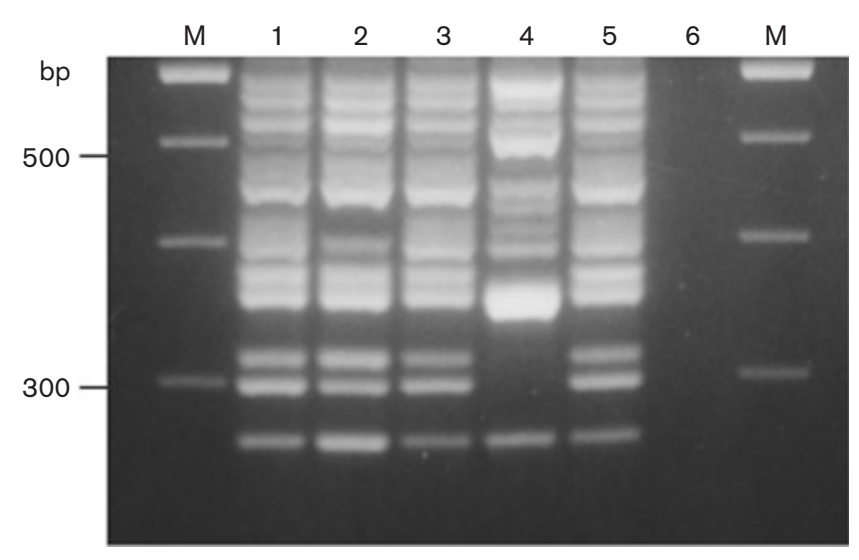

Fig. 1. $P C R$ ribotype patterns of representative isolates typed as s/pA sequence type gc8. Lanes: 1, DJNS 5-23 (s/pA sequence type gc8-01); 2, JND 10-61 (gc8-01); 3, JND 8-64 (gc8-06); 4, DJNS 7-18 (gc8-05); 5, US42 (gc8-01); 6, negative control; M, $100 \mathrm{bp}$ ladder as a molecular size marker. Strain US42 was used as the reference strain of PCR ribotype 027. strain US42. More studies are needed to identify this isolate as a strain related to the hypervirulent strain. DJNS 7-18 was a toxin A-negative, toxin B-positive, CDT-positive isolate with the same deletions in $t c d A$ and $t c d C$ as those of strain 8864 (Lyerly et al., 1992; Rupnik et al., 1998). Since strain 8864 was not available in the present study, PCR ribotyping and $s l p A$ sequence typing results for strain 8864 could not be compared to those for DJNS 7-18. DJNS 7-18 was unique among our collection of clinical isolates in Japan. Additional studies using more clinical isolates are warranted to determine the significance of isolates typed as slpA sequence type gc8 but not as PCR ribotype 027.

PCR ribotype 027 has been reported to be responsible for multiple outbreaks and a major portion of the increase in C. difficile infection rates in North America and Europe (Kuijper et al., 2008; Pépin et al., 2004; Loo et al., 2005; McDonald et al., 2005). It has been documented that patients infected with the PCR ribotype 027 strain are more likely to have severe disease and to have been specifically treated with metronidazole or vancomycin (Barbut et al., 2007). Goorhuis et al. (2007) demonstrated that clear trends were observed for more severe diarrhoea, higher attributable mortality and more recurrences in patients infected with PCR ribotype 027 than in those infected with other types (Goorhuis et al., 2007). The significant pathogenicity of this strain, such as robust toxin production or significantly more spore formation (Merrigan et al., 2010; Warny et al., 2005), may contribute to the severity and wide spread of $C$. difficile infection caused by the strain. These reports indicate that PCR ribotype 027 is more likely to cause outbreaks with high morbidity and mortality. Particularly in the countries or areas where the strain is not currently predominant, such as in Japan (Kato et al., 2007; Sawabe et al., 2007), earlier recognition of outbreaks caused by the strain will provide beneficial information for public health centres, leading to alerts of 


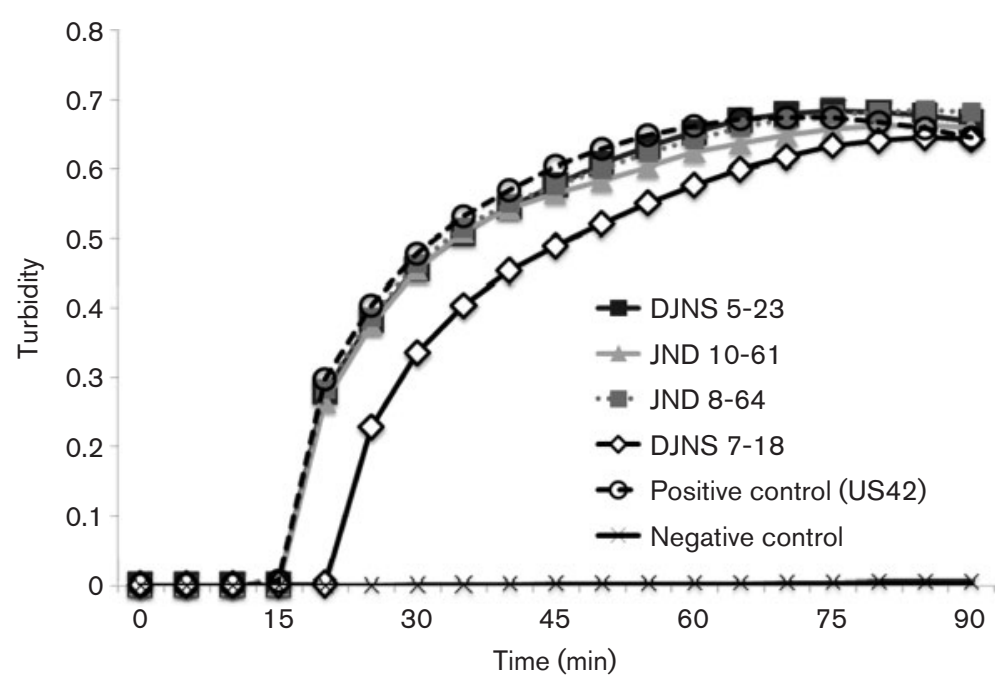

Fig. 2. Real-time turbidity of LAMP amplification products for representative isolates typed as $s / p A$ sequence type gc8. Strain US42 was used as a positive control.

the emergence of the strain to health-care facilities covered by the public centres. The LAMP assay detecting $s l p A-g c 8$ may be valuable for monitoring trends in the prevalence of C. difficile infection caused by PCR ribotype 027 . Since the LAMP method is simple to perform and does not require any special equipment, such as a thermal cycler or electrophoresis system, it is accessible to even small laboratories of local public health centres as well as of health-care facilities.

The LAMP assay detecting $s l p A-g c 8$ proved to be a reliable tool for the identification of PCR ribotype 027 in the present study. The method may be applied to the direct detection of $s l p A-g c 8$ from stool specimens without a culture step. In the present study, one stool specimen from a patient who suffered from pseudomembranous colitis caused by PCR ribotype 027 was available (Kato et al., 2007); detection of $s l p A-g c 8$ was performed on DNA extracted directly from the stool specimen as previously described (Kato et al., 2005), with a positive result (data not shown). Further analysis using a large number of stool specimens is required to evaluate the method for the direct detection of PCR ribotype 027 strains from stool specimens.

\section{ACKNOWLEDGEMENTS}

The authors would like to thank G. E. Killgore, B. Limbago, A. Thompson, L. C. McDonald (Centers for Disease Control and Prevention, US), S. Johnson, W. Zukowski, S. P. Sambol, D. N. Gerding (Hines VA Hospital, US), J. Brazier (University Hospital of Wales, UK), E. J. Kuijper, R. J. van den Berg, D. Bakker (Leiden University Medical Center, The Netherlands), J. Pépin, E. H. Frost (University of Sherbrooke, Canada), B. Nicholson, C. Woods (Duke University School of Medicine, US), P. Savelkoul (VU University Medical Center, The Netherlands), Y. Ito (Gifu Red Cross Hospital, Japan), H. Kato, A. Nakamura, Y. Iwashima, Y. Wakimoto (Nagoya City University Hospital, Japan), C. Sakai, H. Satomura (Chiba Cancer Center, Japan), S. Nakamura, S. Senda (Tokoname City Hospital, Japan), E. Sawabe (Tokyo Medical and Dental University Hospital, Japan) and E. Kano (Hyogo Prefectural Nishinomiya Hospital, Japan) for providing $C$. difficile strains and strain information. The technical assistance of Y. Yoshimura, K. Kai and Y. Taki is also gratefully acknowledged. A grant from the Ministry of Health, Labor and Welfare, Japan (H22-Shinko-Ippan-003) supported this study. This paper was presented at the Third International Clostridium difficile Symposium, Bled, Slovenia, 22-24 September 2010.

\section{REFERENCES}

Barbut, F., Mastrantonio, P., Delmée, M., Brazier, J., Kuijper, E., Poxton, I. on behalf of the European Study Group on Clostridium difficile (ESGCD) (2007). Prospective study of Clostridium difficile infections in Europe with phenotypic and genotypic characterisation of the isolates. Clin Microbiol Infect 13, 1048-1057.

Braun, V., Hundsberger, T., Leukel, P., Sauerborn, M. \& von EichelStreiber, C. (1996). Definition of the single integration site of the pathogenicity locus in Clostridium difficile. Gene 181, 29-38.

Delmée, M., Laroche, Y., Avesani, V. \& Cornelis, G. (1986). Comparison of serogrouping and polyacrylamide gel electrophoresis for typing Clostridium difficile. J Clin Microbiol 24, 991-994.

Gerding, D. N. (2010). Global epidemiology of Clostridium difficile infection in 2010. Infect Control Hosp Epidemiol 31 (Suppl. 1), S32-S34.

Goorhuis, A., Van der Kooi, T., Vaessen, N., Dekker, F. W., Van den Berg, R., Harmanus, C., van den Hof, S., Notermans, D. W. \& Kuijper, E. J. (2007). Spread and epidemiology of Clostridium difficile polymerase chain reaction ribotype 027/toxinotype III in The Netherlands. Clin Infect Dis 45, 695-703.

Goorhuis, A., Bakker, D., Corver, J., Debast, S. B., Harmanus, C., Notermans, D. W., Bergwerff, A. A., Dekker, F. W. \& Kuijper, E. J. (2008). Emergence of Clostridium difficile infection due to a new hypervirulent strain, polymerase chain reaction ribotype 078. Clin Infect Dis 47, 1162-1170.

Kato, N., Ou, C. Y., Kato, H., Bartley, S. L., Brown, V. K., Dowell, V. R., Jr \& Ueno, K. (1991). Identification of toxigenic Clostridium difficile by the polymerase chain reaction. J Clin Microbiol 29, 33-37.

Kato, H., Kato, N., Watanabe, K., Iwai, N., Nakamura, H., Yamamoto, T., Suzuki, K., Kim, S. M., Chong, Y. \& Wasito, E. B. (1998). Identification of toxin A-negative, toxin B-positive Clostridium difficile by PCR. J Clin Microbiol 36, 2178-2182.

Kato, H., Kato, N., Katow, S., Maegawa, T., Nakamura, S. \& Lyerly, D. M. (1999). Deletions in the repeating sequences of the toxin A gene of 
toxin A-negative, toxin B-positive Clostridium difficile strains. FEMS Microbiol Lett 175, 197-203.

Kato, H., Yokoyama, T., Kato, H. \& Arakawa, Y. (2005). Rapid and simple method for detecting the toxin $\mathrm{B}$ gene of Clostridium difficile in stool specimens by loop-mediated isothermal amplification. J Clin Microbiol 43, 6108-6112.

Kato, H., Ito, Y., van den Berg, R. J., Kuijper, E. J. \& Arakawa, Y. (2007). First isolation of Clostridium difficile 027 in Japan. Euro Surveill 12, E070111-E070113.

Kato, H., Kato, H., Ito, Y., Akahane, T., Izumida, S., Yokoyama, T., Kaji, C. \& Arakawa, Y. (2010). Typing of Clostridium difficile isolates endemic in Japan by sequencing of $s l p A$ and its application to direct typing. J Med Microbiol 59, 556-562.

Killgore, G., Thompson, A., Johnson, S., Brazier, J., Kuijper, E., Pépin, J., Frost, E. H., Savelkoul, P., Nicholson, B. \& other authors (2008). Comparison of seven techniques for typing international epidemic strains of Clostridium difficile: restriction endonuclease analysis, pulsedfield gel electrophoresis, PCR-ribotyping, multilocus sequence typing, multilocus variable-number tandem-repeat analysis, amplified fragment length polymorphism, and surface layer protein A gene sequence typing. J Clin Microbiol 46, 431-437.

Kuijper, E. J., Barbut, F., Brazier, J. S., Kleinkauf, N., Eckmanns, T., Lambert, M. L., Drudy, D., Fitzpatrick, F., Wiuff, C. \& other authors (2008). Update of Clostridium difficile infection due to PCR ribotype 027 in Europe, 2008. Euro Surveill 13, 433-439.

Loo, V. G., Poirier, L., Miller, M. A., Oughton, M., Libman, M. D., Michaud, S., Bourgault, A. M., Nguyen, T., Frenette, C. \& other authors (2005). A predominantly clonal multi-institutional outbreak of Clostridium difficile-associated diarrhea with high morbidity and mortality. N Engl J Med 353, 2442-2449.

Lyerly, D. M., Barroso, L. A., Wilkins, T. D., Depitre, C. \& Corthier, G. (1992). Characterization of a toxin A-negative, toxin B-positive strain of Clostridium difficile. Infect Immun 60, 4633-4639.

MacCannell, D. R., Louie, T. J., Gregson, D. B., Laverdiere, M., Labbe, A. C., Laing, F. \& Henwick, S. (2006). Molecular analysis of Clostridium difficile PCR ribotype 027 isolates from Eastern and Western Canada. J Clin Microbiol 44, 2147-2152.
McDonald, L. C., Killgore, G. E., Thompson, A., Owens, R. C., Jr, Kazakova, S. V., Sambol, S. P., Johnson, S. \& Gerding, D. N. (2005). An epidemic, toxin gene-variant strain of Clostridium difficile. $N$ Engl J Med 353, 2433-2441.

Merrigan, M., Venugopal, A., Mallozzi, M., Roxas, B., Viswanathan, V. K., Johnson, S., Gerding, D. N. \& Vedantam, G. (2010). Human hypervirulent Clostridium difficile strains exhibit increased sporulation as well as robust toxin production. J Bacteriol 192, 4904-4911.

Pépin, J., Valiquette, L., Alary, M. E., Villemure, P., Pelletier, A., Forget, K., Pépin, K. \& Chouinard, D. (2004). Clostridium difficileassociated diarrhea in a region of Quebec from 1991 to 2003: a changing pattern of disease severity. CMAJ 171, 466-472.

Rupnik, M., Avesani, V., Janc, M., von Eichel-Streiber, C. \& Delmée, M. (1998). A novel toxinotyping scheme and correlation of toxinotypes with serogroups of Clostridium difficile isolates. J Clin Microbiol 36, 2240-2247.

Sawabe, E., Kato, H., Osawa, K., Chida, T., Tojo, N., Arakawa, Y. \& Okamura, N. (2007). Molecular analysis of Clostridium difficile at a university teaching hospital in Japan: a shift in the predominant type over a five-year period. Eur J Clin Microbiol Infect Dis 26, 695-703.

Spigaglia, P. \& Mastrantonio, P. (2002). Molecular analysis of the pathogenicity locus and polymorphism in the putative negative regulator of toxin production (TcdC) among Clostridium difficile clinical isolates. J Clin Microbiol 40, 3470-3475.

Stubbs, S. L., Brazier, J. S., O'Neill, G. L. \& Duerden, B. I. (1999). PCR targeted to the 16S-23S rRNA gene intergenic spacer region of Clostridium difficile and construction of a library consisting of 116 different PCR ribotypes. J Clin Microbiol 37, 461-463.

Stubbs, S., Rupnik, M., Gibert, M., Brazier, J., Duerden, B. \& Popoff, M. (2000). Production of actin-specific ADP-ribosyltransferase (binary toxin) by strains of Clostridium difficile. FEMS Microbiol Lett 186, 307312.

Warny, M., Pépin, J., Fang, A., Killgore, G., Thompson, A., Brazier, J., Frost, E. \& McDonald, L. C. (2005). Toxin production by an emerging strain of Clostridium difficile associated with outbreaks of severe disease in North America and Europe. Lancet 366, 1079-1084. 